\title{
A disruption production model with exponential demand
}

\author{
U. K. Khedlekar
}

Department of Mathematics and Statistics, Sagar Central University, Sagar M.P. India, 470003

\begin{tabular}{|c|c|}
\hline AR T I C L E I N F O & A B S T R A C T \\
\hline $\begin{array}{l}\text { Article history: } \\
\text { Received 25 January } 2012 \\
\text { Accepted March, } 102012 \\
\text { Available online } \\
14 \text { March } 2012 \\
\text { Keywords: } \\
\text { Inventory } \\
\text { Disrupted Production System, } \\
\text { Deterioration }\end{array}$ & $\begin{array}{l}\text { In general, production system often gets disrupted due to uncertainty and un-planned events, } \\
\text { which also affect demands resulting in less abet-margin of a company. With disrupted production } \\
\text { system, management would need to study the variation of demand pattern and disruption of } \\
\text { system; we have attempted an effort to establish an exponential demand with the disrupted } \\
\text { production system and solved analytically the problem to determine production time before and } \\
\text { after disruptions. Exponentially demand pattern studied, and also we simulate the results for } \\
\text { sensitivity analysis in order to find which parameter is getting significant change for the proposed } \\
\text { model. }\end{array}$ \\
\hline
\end{tabular}

\section{Introduction}

Control and maintenance of the production system have attracted much attention of inventory managers. There are many reasons for disruptions of the production system like machine breakdown, unexpected events or some crises. An oil drilling company may be disrupted due to electricity supply, failure of drilling machines whereas oil refining company faces some problem of crude oil supply and availability of other raw materials or due to earthquake and strike. Lin and Kroll (2006) solved the production problem under an imperfect production system subject to random breakdowns.

Teng and Chang (2005) presented an economic production quantity model for deteriorating items when the demand rate depends on not only on-display stock, but also on the selling price per unit of an item which may influence by economic policy, political scenario or agriculture productivity or both get affected. A similar approach has been followed by Hou and Lin (2006) on the deterministic economic order quantity model by taking into account the inflation and the time value of money for the deteriorating items with price and stock-dependent selling rate. Liao (2007) established an EPQ model by giving permission to delay in payment for the buyer to manufacturers. A single vendor and multibuyer inventory policy for a deteriorating item was made by Yang and Wee (2002). By dividing the demand rate into multiple segments, Shukla and Khedlekar (2010) introduced three-component demand

* Corresponding author. Tel.: +91-9425861689

E-mail uvkkcm@yahoo.co.in (U. K. Khedlekar)

(C) 2012 Growing Science Ltd. All rights reserved. doi: $10.5267 / j$. .ijiec.2012.03.006 
rate for the newly launched deteriorating item. Joglekar (2003) used a linear demand function with price sensitiveness and allowed retailers to use a continuous increasing price strategy in an inventory cycle. He derived the retailer's optimal profit by ignoring all the inventory costs. His findings are restricted to growing market only, which is neither for stable market nor for a declining market.

Joglekar (2003) used a linear demand function with price sensitiveness and allowed retailers to use a continuous increasing price strategy in an inventory cycle. He derived the retailer's optimal profit by ignoring all the inventory costs. His findings are not restricted to growing market only, which is neither for stable market nor for a declining market. By dividing the demand rate into multiple segments, Shukla and Khedlekar (2010) introduced three-component demand rate for the newly launched deteriorating item. Qi, Bard and Yu (2004) analyzed the supply chain-coordination with demand disruption in a deterministic scenario. Expenditure sources like ordering cost, safety features, lead time and numbers of lots are the integral parts of decision making. An integrated inventory model focusing on these issues and aspects has been discussed by Lo (2007).

Giri et al. (1996) who computed the optimal policy of an EOQ model with dynamic costs. The model they proposed is very basic though, since they have considered the very special case where the holding and ordering costs are linear functions of time. The other shortcoming of that paper is that the deterioration rate is also a linear function of time, and the algorithm they proposed in order to solve the problem is only valid as long as the demand rate is a linear function of time.

Samanta and Roy (2004) studied a number of structural properties of the inventory system analytically by determination of production cycle time and backlog for deteriorating item, which follows an exponential distribution. They (2010) obtained optimal production time to facilitate the manufacturer sell the item in multiple markets by considering constant demand rate, but they do not readjust the production system. Due to above contribution time dependent demand is influenced to consider for deteriorating item and adjust the disrupted production system with shortages and when it occurs an optimal time of placing an order is obtained along with order quantity from the spot market. A central policy presented by Benjaafar EIHafsi (2006) specify a single product assemble-to-order system for my components, an end-product to serve and customer classes and problem solved as a Markov decision process and characterize the structure of an optimal policy. We refer some useful contribution to reader Balkhi and Bakry (2009), AI -Majed (2002), Khedlekar and Agarwal (2009), Mishra and Mishra (2010) and Shukla et al. (2012).

\section{Assumptions and notations}

Suppose that a deteriorating item manufactured by a single manufacturer and then sold to customers, the demand arising from the market is exponentially at a rate $\mu e^{c t}$, the production rate is constant at a rate $p>\mu$ in each cycle; due to this inventory accumulate at a rate $p-\mu e^{c t}$. If the production stopped at the time $\left(T_{p}\right)$ and thus there after inventory depicted due to the demand and deterioration. During production disruption, if shortages occur, then it ordered from the spot market once in a cycle.

$\begin{array}{ll}H & \text { Time horizon, } \\ P & \text { Production rate, } \\ \theta & \text { Rate of deterioration, } \\ \mu & \text { Initial demand of item, } \\ \mu e^{c t} & \text { demand function of item, } \\ T_{p} & \text { Production time without disruption, }\end{array}$


$T_{d} \quad$ Production disruption time when system get disruptions,

$T_{p}{ }^{d} \quad$ New production time after system get disruptions,

$T_{r} \quad$ Time of placing the order when shortages occur,

$Q_{r} \quad$ Order quantity (shortages) for placing the order when shortage occurs.

\section{The production model without disruption}

To compare the model output first, management optimizes the production system run without disruption with production rate $\mathrm{p}$ (per unit time) stopped at production time $T_{p}$ and there after till time $H$, inventory depicted due to demand rate $\mu$ ect and deterioration rate $\theta$ of items (see fig. 1). The presentations in differential equations for two periods $\left[0, T_{p}\right]$ and $\left[T_{p}, H\right]$ satisfy throughout its domain.

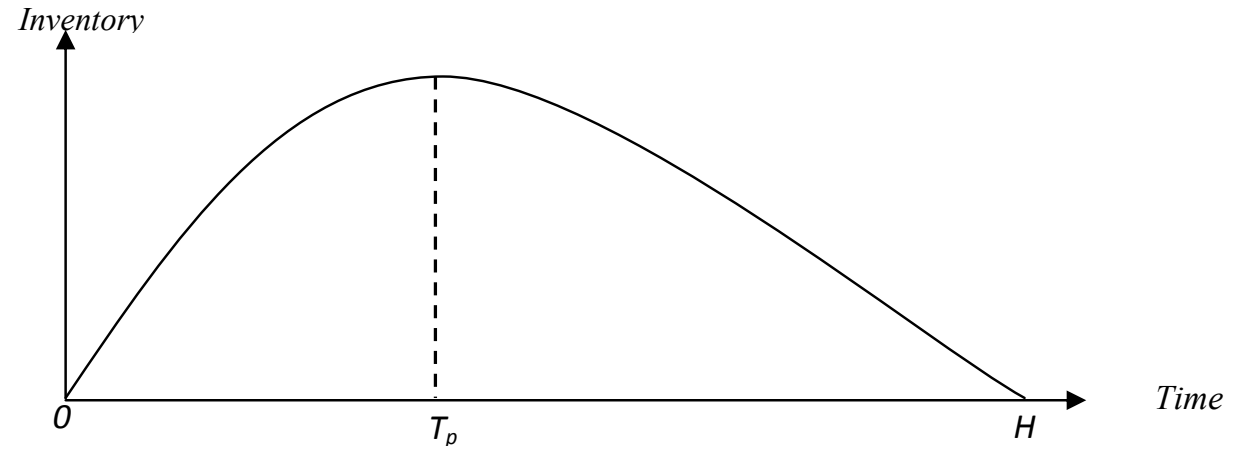

Fig. 1. (Normal Production System without disruption)

$\frac{d I_{1}(t)}{d t}+\theta I_{1}(t)=p-\mu e^{c t}, 0 \leq t \leq T_{p}$ boundary condition $I_{1}(0)=0$

$\frac{d I_{2}(t)}{d t}+\theta I_{2}(t)=-\mu e^{c t}, T_{p} \leqslant t \leqslant H$ boundary condition $I_{2}(H)=0$

On solving equation (1) and (2) with boundary conditions we get

$$
\begin{aligned}
& I_{1}(t)=\frac{p}{\theta}\left(1-e^{-\theta t}\right)-\frac{\mu}{c+\theta}\left(e^{c t}-e^{-\theta t}\right) \\
& I_{2}(t)=\frac{\mu}{c+\theta}\left(e^{(c+\theta) H-\theta t}-e^{c t}\right)
\end{aligned}
$$

As per fig. 1 inventory level $I_{1}(\mathrm{t})$ and $I_{2}(\mathrm{t})$ are equal at time Tp

i.e. $\quad I_{1}\left(T_{p}\right)=I_{2}\left(T_{p}\right)$ yields

$T_{p}=\frac{1}{\theta} \log \frac{P c+\theta P-\theta \mu+\theta \mu e^{c H+\theta H}}{P c+P \theta}$

If $\theta<<1$, then 


$$
T_{p}=\frac{\mu e^{c H}(1+\theta H)-\mu}{P c+P \theta-\mu \theta+\mu e^{c H}}
$$

\section{The production model with disruption}

In section 3 production rate unchanged but in practice production system is always disruption due to unplanned and thus we consider the production system little changed by $\Delta P$ and disruption time is $T_{d}$. If $\Delta P<0$, then production rate decreases and, if $\Delta P>0$ then production rate increases.

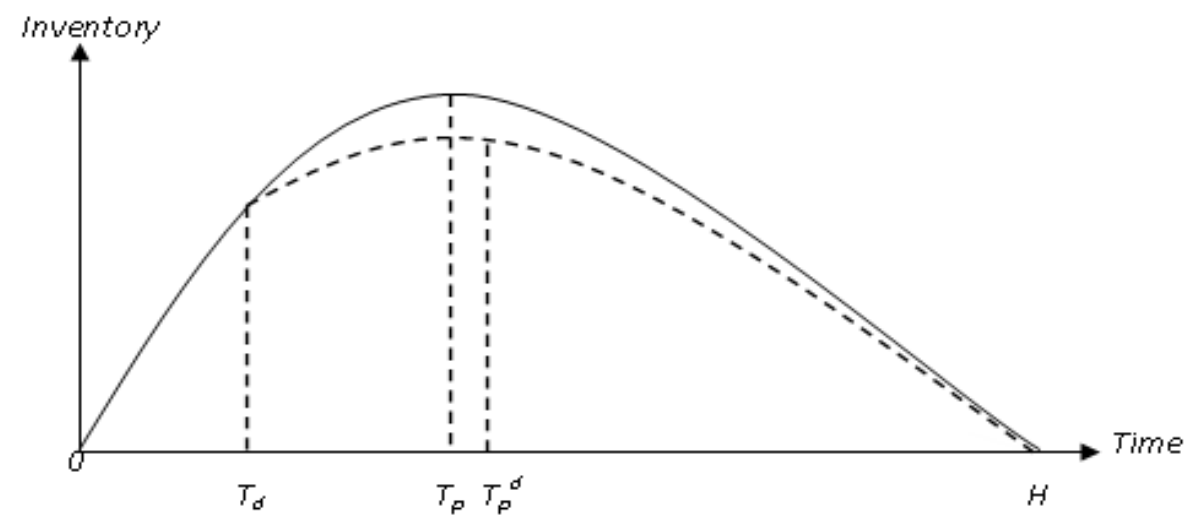

Fig. 2. Disrupted Production System

Lemma 1. If $\Delta P \geqslant\left(P(c+\theta) e^{-\theta H}-P(c+\theta)+\mu \theta\left(e^{c H}-e^{-H \theta}\right)\right) /(c+\theta)\left(1-e^{\theta T_{d}-H \theta}\right)$ then manufacturing system still satisfies the exponential demand even production system has been disrupted, otherwise If $-P \leqslant \Delta P \geqslant\left(P(c+\theta) e^{-\theta H}-P(c+\theta)+\mu \theta\left(e^{c H}-e^{-H \theta}\right)\right) /(c+\theta)\left(1-e^{\theta T_{d}-H \theta}\right)$ then production system unable to satisfy exponential demand that is there will be shortages due to production disruption.

Proof: Suppose the production system disrupted at time $T_{d}$ as (see Fig. 2) and there after the production rate will be $P+\Delta P$ thus presentations of two differential equations for intervals $\left[0, T_{d}\right]$ and $\left[T_{d}, H\right]$ are

$\frac{d I_{1}(t)}{d t}+\theta I_{1}(t)=p-\mu e^{c t}, 0 \leqslant t \leqslant T_{d}$ boundary condition $I_{1}(0)=0,0<\theta<1$

$\frac{d I_{2}(t)}{d t}+\theta I_{2}(t)=P+\Delta P-\mu e^{c t}, T_{d} \leqslant t \leqslant H$,

with boundary condition $I_{1}\left(T_{d}\right)=I_{2}\left(T_{d}\right)=\frac{p}{\theta}\left(1-e^{-\theta T_{d}}\right)-\frac{\mu}{c+\theta}\left(e^{c T_{d}}-e^{-\theta T_{d}}\right)$

On solving Eq. (8) with boundary condition we get

$$
I_{2}(t)=\frac{P}{\theta}\left(1-e^{-\theta t}\right)+\frac{\Delta P}{\theta}\left(1-e^{\theta T_{d}-\theta t}\right)+\frac{\mu}{c+\theta}\left(e^{-\theta t}-e^{c t}\right)
$$

If $I_{2}(H) \geqslant 0$ this means production system satisfy the exponential demand of items

That is $\Delta P \geqslant \frac{P(c+\theta) e^{-\theta H}-P(c+\theta)+\mu \theta\left(e^{c H}-e^{-H \theta}\right)}{(c+\theta)\left(1-e^{\theta T_{d}-H \theta}\right)}$ then still satisfy the demand

If $I_{2}(H)<0$ this means production system does not satisfy the exponential demand of items 
That is $-P \leqslant \Delta P<\frac{P(c+\theta) e^{-\theta H}-P(c+\theta)+\mu \theta\left(e^{c H}-e^{-\theta H}\right)}{(c+\theta)\left(1-e^{\theta T_{d}-H \theta}\right)}$ then there will be shortages in the system.

This proved the lemma*

Again, if $I_{2}(H) \geq 0$ then we find optimal production time (with disruption) $T_{p}^{d}$ such that at time $H$ entire stock will be sold-out and inventory level will be zero.

If $I_{2}(H)<0$ there will be shortages in the system and in this situation we will find the optimum time $T_{r}$ of placing the order and respective order quantity $Q_{r}$.

Lemma 2. If $I_{2}(H) \geq 0$ then production time with disruption $T_{p}^{d}$ is obtained by

$$
e^{\theta T_{p}^{d}}=\frac{\mathrm{Pc}+\mathrm{P} \theta-\mu \theta+\Delta \mathrm{P}(\mathrm{c}+\theta) \mathrm{e}^{\theta \mathrm{T}_{\mathrm{d}}}+\mu \theta \mathrm{e}^{\mathrm{c} \theta+\mathrm{H} \theta}}{(\mathrm{P}+\Delta \mathrm{P})(\mathrm{c}+\theta)}
$$

Proof: If $I_{2}(H) \geq 0$

or $\Delta P \geqslant \frac{P(c+\theta) e^{-\theta H}-P(c+\theta)+\mu \theta\left(e^{c H}-e^{-\theta H}\right)}{(c+\theta)\left(1-e^{\theta T_{d}-H \theta}\right)}$ that is on hand inventory is $I_{2}(H)$

Therefore we will find out the optimal time $T_{p}^{d}$ (see fig. 3) when we stopped the production after disruption in such a manner that stock remains zero at time $H$. the presentations of two differential equations for intervals $\left[T_{d}, T_{p}^{d}\right]$ and $\left[T_{p}{ }^{d}, H\right]$ are

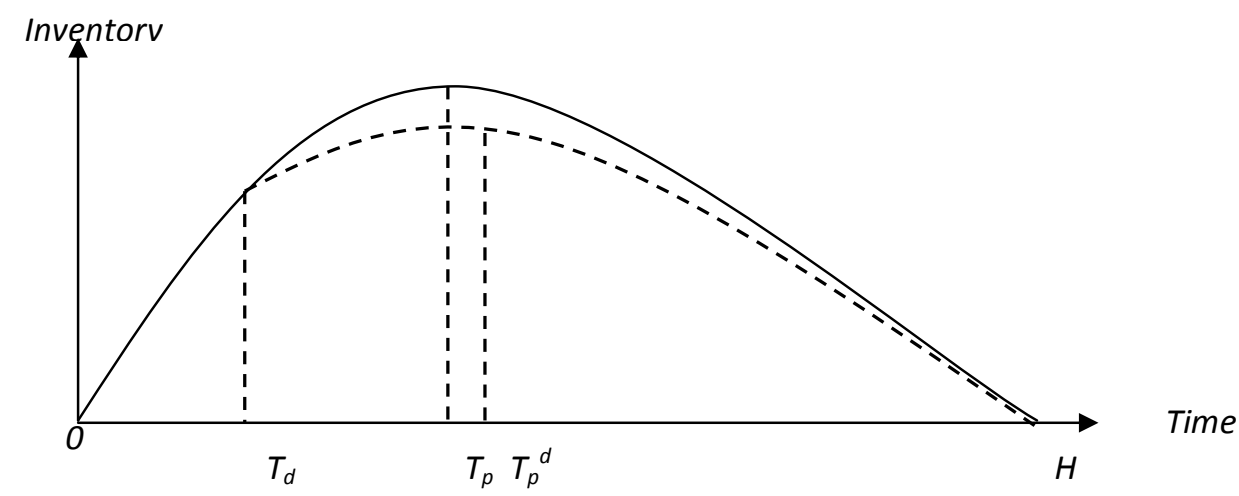

Fig. 3. Production System after Disruption, $0 \leq T_{d} \leq T_{p} \leq T_{p}{ }^{d} \leq H$

$\frac{d I_{2}(t)}{d t}+\theta I_{2}(t)=p+\Delta P-\mu e^{c t}, T_{d} \leqslant t \leqslant T_{p}^{d}$

Boundary condition $I_{1}\left(T_{d}\right)=I_{2}\left(T_{d}\right)=\frac{p}{\theta}\left(1-e^{-\theta T_{d}}\right)-\frac{\mu}{c+\theta}\left(e^{c T_{d}}-e^{-\theta T_{d}}\right)$

$\frac{d I_{3}(t)}{d t}+\theta I_{3}(t)=-\mu e^{c t}, T_{d} \leqslant t \leqslant H$ boundary condition $I_{3}(H)=0$

On solving (12) with boundary condition we get

$I_{2}(t)=-\frac{p}{\theta}\left(e^{\theta T_{d}}-1\right) e^{-\theta t}+\frac{\mu}{c+\theta}\left(e^{c T_{d}+\theta T_{d}}-1\right) e^{-\theta t}+\frac{P+\Delta P}{\theta}\left(1-e^{\theta T_{d}-\theta t}\right)-\frac{\mu}{c+\theta}\left(e^{-c t}-e^{(c+\theta) T_{d}-\theta t}\right)$ 
$I_{3}(t)=\frac{\mu}{c+\theta}\left(e^{c H+\theta H-\theta t}-e^{c t}\right)$

Using condition $I_{2}\left(T_{p}^{d}\right)=I_{3}\left(T_{p}^{d}\right)$

$$
e^{\theta T_{p}^{d}}=\frac{\mathrm{Pc}+\mathrm{P} \theta-\mu \theta+\Delta \mathrm{P}(\mathrm{c}+\theta) \mathrm{e}^{\theta \mathrm{T}_{d}}+\mu \theta \mathrm{e}^{\mathrm{c} \theta+\mathrm{H} \theta}}{(\mathrm{P}+\Delta \mathrm{P})(\mathrm{c}+\theta)} \text { - }
$$

Therefore increases in $T_{d}$ leads the production time with disruption $T_{p}^{d}$ increases that is reduced incurred cost.

Lemma 3. If $I_{2}(H)<0$ then replenishment time $T_{r}$ and order quantity $Q_{r}$ are

$$
\begin{aligned}
& e^{-\theta T_{r}}\left(P c+P \theta-\mu \theta+\Delta P(c+\theta) e^{\theta T_{d}}\right)+\mu \theta e^{c T_{r}}+(P+\Delta P)(c+\theta)=0 \\
Q_{r}= & I_{3}\left(T_{r}\right)=\frac{P+\Delta P}{\theta}\left(1-\mathrm{e}^{\theta H-\theta \mathrm{T}_{\mathrm{r}}}\right)-\frac{\mu}{c+\theta}\left(e^{c T_{r}}-\mathrm{e}^{\mathrm{cH}+\theta \mathrm{H}-\theta \mathrm{T}_{\mathrm{r}}}\right)
\end{aligned}
$$

Proof: If $I_{2}(H)<0$ then production system does not fulfill the exponential demand Or $-P \leq \Delta P<\frac{P(c+\theta) e^{\theta-\theta H}-P(c+\theta)+\mu \theta\left(e^{c H}-e^{-\theta H}\right)}{(c+\theta)\left(1-e^{\theta T_{d}-H \theta}\right)}$ that is there will be shortages in the system.

Suppose Tr and Qr (see Fig. 4) are time of placing an order and order quantity respectively.

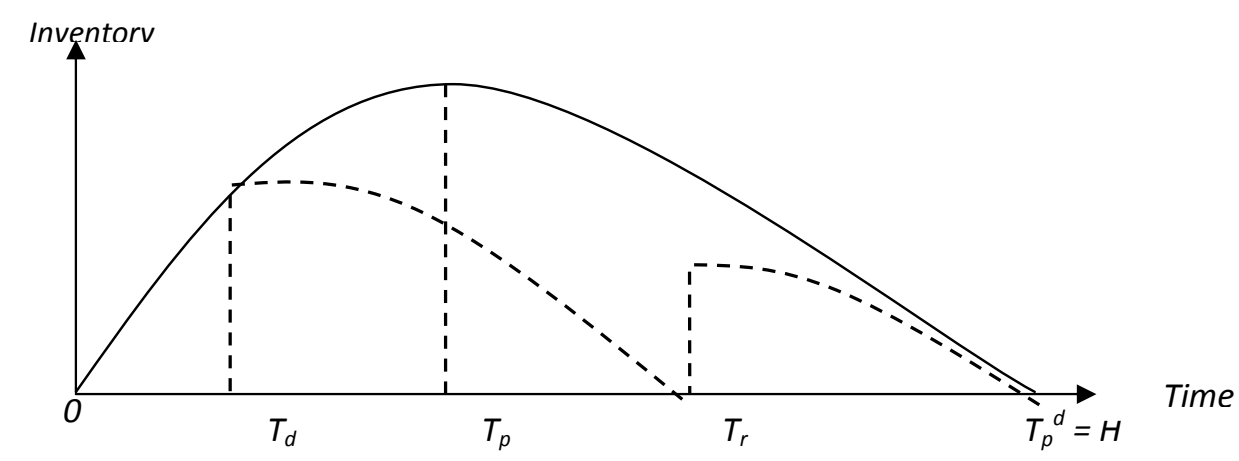

Fig. 4. (Production System after Disruption, $T_{p}{ }^{d}=H$ )

Then $I_{2}\left(T_{r}\right)=0$ (by Eq. (14)

$$
\left(\frac{\Delta \mathrm{P}-\mathrm{P}}{\theta} e^{\theta T_{r}}+\frac{\mu}{\mathrm{c}+\theta} \mathrm{e}^{\mathrm{c} \mathrm{T}_{\mathrm{r}}+\theta T_{r}}\right)=\frac{\mu}{c+\theta}-\frac{P}{\theta}-\frac{\Delta P}{\theta} e^{\theta T_{d}}
$$

or $e^{-\theta T_{r}}\left(P c+P \theta-\mu \theta+\Delta P(c+\theta) e^{\theta T_{d}}\right)+\mu \theta e^{c T_{r}}+(P+\Delta P)(c+\theta)=0$

Then presentation of differential equation in this situation is

$\frac{d I_{3}(t)}{d t}+\theta I_{3}(t)=P+\Delta P-\mu e^{c t}, T_{r} \leqslant t \leqslant H$ boundary condition $I_{3}(H)=0$ Above equation gives 


$$
I_{3}(t)=\frac{P+\Delta P}{\theta}\left(1-e^{\theta H-\theta t}\right)-\frac{\mu}{c+\theta}\left(e^{c T_{r}}-e^{c H+\theta H-\theta t}\right)
$$

Hence the order quantity is $Q_{r}=I_{3}\left(T_{r}\right)$

$Q_{r}=I_{3}\left(T_{r}\right)=\frac{P+\Delta P}{\theta}\left(1-\mathrm{e}^{\theta H-\theta \mathrm{T}_{\mathrm{r}}}\right)-\frac{\mu}{c+\theta}\left(e^{c T_{r}}-\mathrm{e}^{\mathrm{cH}+\theta \mathrm{H}-\theta \mathrm{T}_{\mathrm{r}}}\right)$

\section{Application and sensitive Analysis}

For application we assumed a particular case when $P=350, \mu=200, \Delta P=-200, \theta=.03, c=0, H=20$ and $T_{d}$ $=8$ on applying then we get $I_{2}(H)>0$ and thus by equation (6) and (11) $T_{p}=12.83 T_{p}^{d}=18.3578$.

Following figures shows sensitiveness with respective the $\theta$ and $T_{d}$.

Case I: When $-P \leqslant \Delta P<\left(P(c+\theta) e^{-\theta H}-P(c+\theta)+\mu \theta\left(e^{c H}-e^{-\theta H}\right)\right) /(c+\theta)\left(1-e^{\theta T d-H \theta}\right)$

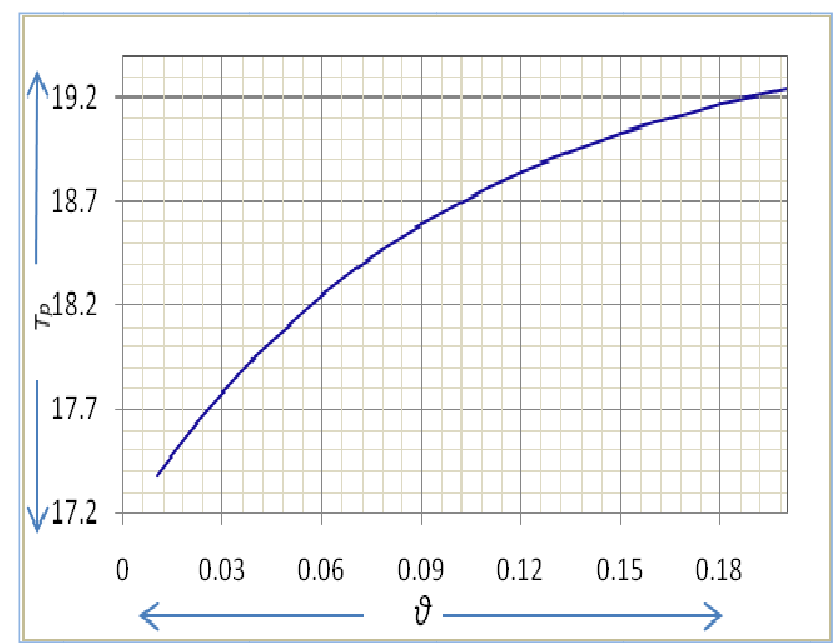

Fig. 5. ( $\mathrm{T}_{\mathrm{p}}$ with repective to $\left.\theta\right)$

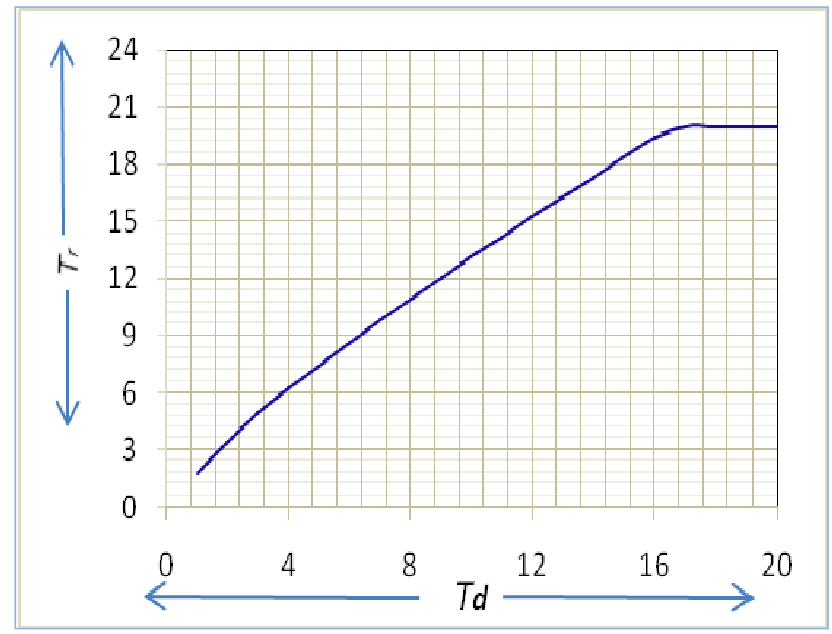

Fig. 7. ( $T_{r}$ with repective to $\left.T_{d}\right)$

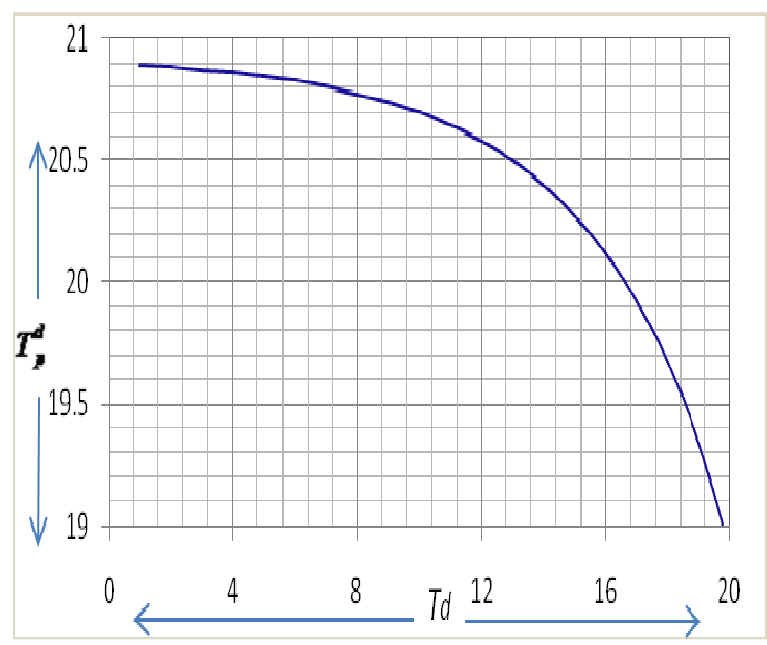

Fig. 6. $\left(T_{p}^{d}\right.$ with repective to $\left.\mathrm{T}_{\mathrm{d}}\right)$

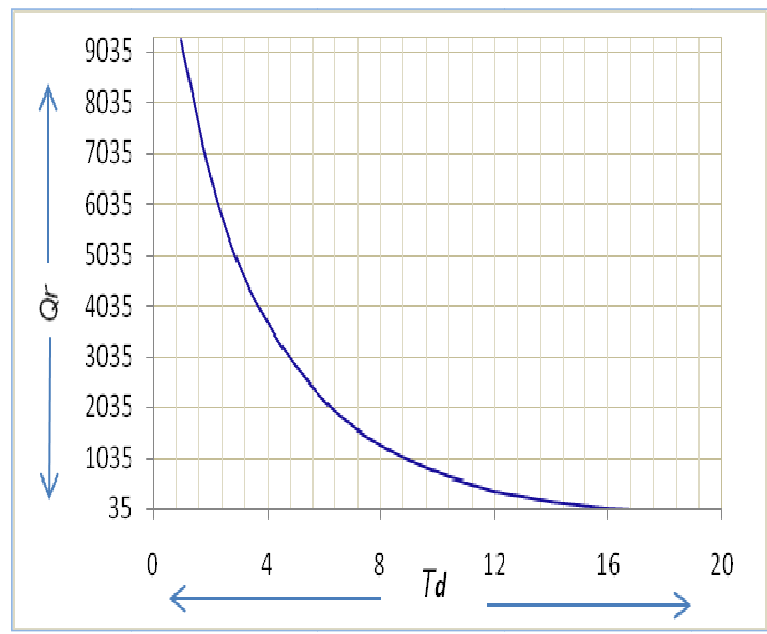

Fig. 8. $\left(Q_{r}\right.$ with repective to $\left.T_{d}\right)$

From Fig. 5, $T_{p}$ is increasing in $\theta$ production time is direct proportional to deterioration means it needed to more manufacturer items. So it is the effective way to reduce the cost as keeping lower deterioration and same followed by Fig. 6. 
If $I_{2}(H)<0$ then there are shortages occurs in system and there is the need to order quantity $Q_{r}$ from the spot market at time $T_{r}$ (Fig. 7) Which decreases as $T_{d}$ increases for $0<T d \leq 17$ and there after constant. Delay in disruption time produces fewer shortage shortages which reduce the incurred cost and same result followed by Fig. 8 .

Case II: When $\Delta P>\left(P(c+\theta) e^{\theta_{-\theta H}}-P(c+\theta)+\mu \theta\left(e^{c H}-e^{-\theta H}\right)\right) /(c+\theta)\left(1-e^{\theta T_{d}-H \theta}\right)$

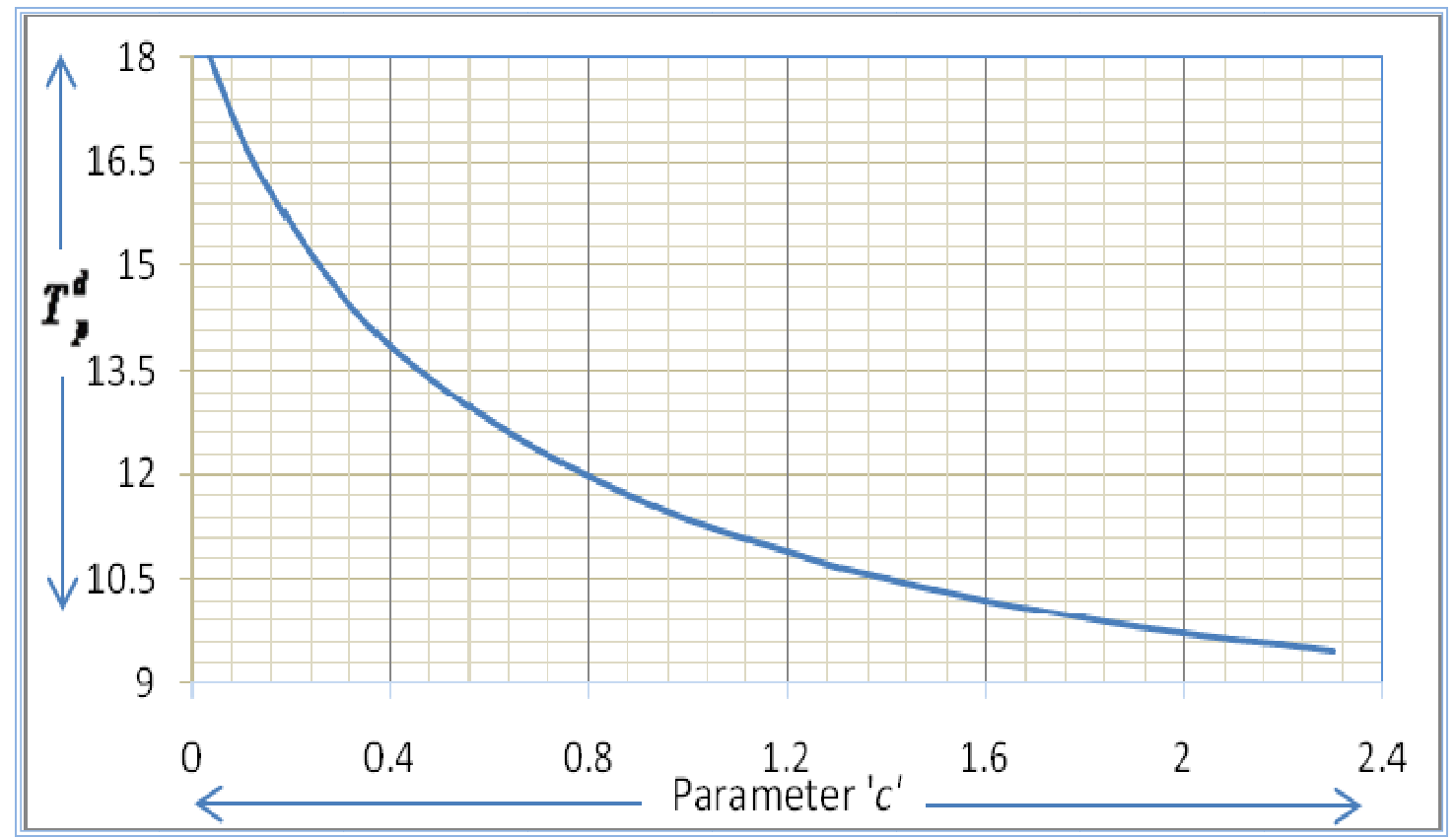

Fig. 9. ( with respective to parameter 'c')

From Fig. 9 time $T_{p}^{d}$ decreases as c increases, which lead in increasing demand that result to start reproduction earlier.

Table 1

Comparison with constant / increasing / decreasing trend of demand

\begin{tabular}{llllccll}
\hline Parameter 'c' & $\begin{array}{l}\text { Demand } \\
\text { Trend }\end{array}$ & $\mathrm{I}_{2}(\mathrm{H})$ & $\mathrm{T}_{\mathrm{p}}$ & $\mathrm{T}_{\mathrm{r}}$ & $\mathrm{Q}_{\mathrm{r}}$ & $T_{p}^{d}$ & $\mathrm{I}_{2}(\mathrm{H})$ \\
\hline 0 & Constant & $\mathrm{I}_{2}(\mathrm{H})<0$ & 19.24 & 10.92 & 1286 & - & - \\
0.02 & Increasing & $\mathrm{I}_{2}(\mathrm{H})<0$ & 20.77 & 21.28 & 7255 & - & - \\
-0.02 & Decreasing & $\mathrm{I}_{2}(\mathrm{H})>0$ & 17.76 & - & - & 8.63 & 176 \\
0.05 & Increasing & $\mathrm{I}_{2}(\mathrm{H})<0$ & 23.12 & 7.12 & 25955 & - & - \\
-0.05 & Decreasing & $\mathrm{I}_{2}(\mathrm{H})>0$ & 15.63 & - & - & 22.23 & 564 \\
0.10 & Increasing & $\mathrm{I}_{2}(\mathrm{H})<0$ & 27.21 & 5.82 & 104115 & - & - \\
-0.10 & Decreasing & $\mathrm{I}_{2}(\mathrm{H})>0$ & 12.40 & - & - & 24.16 & 912 \\
0.15 & Increasing & $\mathrm{I}_{2}(\mathrm{H})<0$ & 31.43 & 5.05 & 317239 & - & - \\
-0.15 & Decreasing & $\mathrm{I}_{2}(\mathrm{H})>0$ & 9.65 & - & - & 27.58 & 1074 \\
\hline
\end{tabular}

As per Table 1, one can observe that exponential increasing/decreasing demand rate are quite different than constant, whenever $c=0$ gives $I_{2}(H)<0$ and order quantity $Q_{r}=1286$. For positive and negative value of $c, I_{2}(H)$ is negative and positive respectively. Order quantity is highly sensitive to demand 
parameter $c$ but adverse to replenishment time, $T_{p}^{d}$ and $I_{2}(H)$ both are highly sensitive to negative trend of demand. This means if demand rate is in increasing management need to order more from the spot market beside this if demand rate is decreases it need to stop the production earlier.

\section{Conclusion and recommendations}

The effect of exponential demand is quite different in terms of disruption time, reproduction time and deteriorations with the disrupted production system. It is found that demand parameter highly affects the optimal policy when system gets disrupted. The combination of two strategies one is increasing and other decreasing is shown to be effective using the different examples. If a demand rate is in increasing trend management needs to order more from the spot market beside this if the demand rate decreases it need to stop the production before the planned time. One can further extend the model by considering the more realistic assumption like time dependent production along with time dependent demand even production system get disrupted. One can also extend the model by computing rates of change of production time before and after disruptions with respect to deterioration and other parameters.

\section{References}

Al-Majed, M. I. (2002). Continuous-time optimal control of deteriorating inventory/production system using a demand observer. Journal King Saud University, 15(1), 81-94.

Balkhi, Z., \& Bakry, A.S.H. (2009). A general and dynamic production lot size inventory model. International Journal of Mathematical Models and Methods in Applied Sciences, 3(3) 187-195.

Benjaafar, S., \& EIHafsi, M (2006). Production and inventory control of a single product assemble-toorder system with multiple customer classes. Management Science, 52(12), 1896-1912.

Giri, B. C. Goswami, A. and Chaudhuri, K. S. (1996). An EOQ model for deteriorating items with time varying demand and costs. Journal of the Operational Research Society, 47(11), 1398-1405.

He, Y. Wang, S.Y., \& Lai, K.K. (2010). An optimal production-inventory model for deteriorating items with multiple-market demand. European Journal of Operational Research, 203(3), 593-600.

Hou, K.L., \& Lin, L.C. (2006). An EOQ model for deteriorating items with price-and stock-dependent selling rates under inflation and value of money. International Journal of System Science, 37(15), 1131-1139.

Joglekar, P. (2003). Optimal price and order quantity strategies for the reseller of a product with pricesensitive demand, Proceeding Academic Information Management Sciences. 7(1) 13-19.

Khedlekar, U. K., \& Agrawal, R. K. (2009). A deterministic order level inventory model for two types of deteriorating items with three storage facility. Reflection Des Era (RDE), 5(1), 201-208.

Liao, J.-J. (2007). On an EPQ model for deteriorating items under permissible delay in payments, Applied Mathematical Modeling. 31(3) 393-403.

Lin, G.C., \& Kroll, D. E. (2006). Economic lot sizing for an imperfect production system subject to random breakdowns. Engineering Optimization. 38(1) 73-92.

Lo, M.C. (2007). Decision supports system for the integrated inventory model with general distribution demand. Information Technology Journal, 6(7), 1069-1074.

Mishra, S. S., \& Mishra, P.P. (2010). Price determination for an EOQ model for deteriorating items under perfect competition. Computer \& Mathematics with Applications, 56(4) 1082-1101.

Qi, X., Bard, J. F., \& Yu, G. (2004). Supply chain coordination with demand disruptions. Omega, 32, 301-312.

Samanta, G.P., \& Roy, A. (2004). A production inventory model with deteriorating items and shortages. Yugoslav Journal of Operations Research, 14(2) 219-230.

Shukla, D., \& Khedlekar, U.K. (2010). An order level inventory model with three-Component demandrate (TCDR) for newly launched deteriorating item. International Journal of Operations Research(IJOR-Taiwan), 7(2) 61-70. 
Shukla, D., Khedlekar, U.K., Chandel, R.P.S., \& Bhagwat, S. (2012). Simulation of inventory policy for product with price and time-dependent demand for deteriorating item. International Journal of Modeling, Simulation, and Scientific Computing, 3(1), 1-30.

Teng, J. T., \& Chang, C. T. (2005). Economic production quantity model for deteriorating items with price and stock dependent demand. Computer \& Operations Research, 32(2) 297-308.

Yang, P. C., \& Wee, H. M. (2002). A single-vendor and multiple-buyers production-inventory policy for a deteriorating items. European Journal of Operational Research, 143(3) 570-581. 